\title{
Faktor-faktor yang mempengaruhi subjective well-being
}

\author{
Lharasati Dewi \\ Magister Psikologi, Program Pascasarjana, Universitas Ahmad Dahlan \\ lharasatidewi@gmail.com \\ Naila Nasywa \\ Magister Psikologi, Program Pascasarjana, Universitas Ahmad Dahlan \\ nailanasywa21@gmail.com
}

\begin{abstract}
ABSTRAK
Subjective well-being merupakan bagaimana individu mengevaluasi hidupnya. Subjective well-being melibatkan evaluasi pada dua komponen, yaitu kognitif dan afektif .Penelitian ini bertujuan untuk mengkaji hasil-hasil penelitian (literature review) mengenai faktor-faktor yang mempengaruhi subjective well-being pada individu.Penelusuran literatur dilakukan pada database elektronik SAGE Journals, ProQuest, dan Science Direct dengan menggunakan kata kunci “subjective well-being".Hasil penelusuran menunjukkan bahwa subjective well-being dipengaruhi oleh faktor internal dan eksternal. Faktor internal yang mempengaruhi subjective well-being terdiri dari kebersyukuran, forgiveness, personality, self-esteem dan spiritualitas sedangkan faktor eksternal terdiri dari dukungan sosial.
\end{abstract}

Kata Kunci : Faktor Eksternal, Faktor Internal, Subjective Well-Being

\begin{abstract}
Subjective well-being is how each individual succeeds. Subjective well-being participates in two components, namely cognitive and affective. This study aims to examine the results of research (literature review) about the factors that affect subjective well-being in individuals. Literature search was carried out on the SAGE Journal, ProQuest, and Science Direct electronic databases using the keywords "subjective well-being". The search results show that subjective well-being is influenced by internal and external factors. Internal factors that affect subjective well-being consist of gratitude, forgiveness, personality, self-esteem and spirituality while external factors consist of social support.
\end{abstract}

Keywords:External Factors, Internal Factors, Subjective Well-being

\section{PENDAHULUAN}

Subjective well-being merupakan hal yang penting dalam hidup seseorang. Seseorang melakukan berbagai cara agar dapat merasakan kesejahteraan dalam hidupnya. Salah satu tujuan seseorang bersemangat menjalani hidup adalah agar bahagia. Subjective well-being merupakan istilah yang memiliki keterkaitan erat dengan kebahagiaan (happiness). Bukhari dan Khanam (2015) menyebutkan bahwa kebahagiaan adalah bagian dalam subjective well-being yang mana hal tersebut merupakan suatu pandangan yang bersifat subjektif dari keseluruhan kehidupan yang dimiliki individu. Selain penting 
Jurnal Psikologi Terapan dan Pendidikan

ISSN: 2715-2456

Vol. 1, No. 1, Mei 2019, pp. 54-62

untuk diteliti dan dipelajari karena menggambarkan kualitas hidup seseorang, subjective well-beingjuga dapat memberikan dampak yang positif bagi kehidupan seseorang. Banyak manfaat yang didapatkan apabila seseorang memiliki tingkat subjective well-being yang tinggi, antara lain manfaat untuk kesehatan salah satunya panjang umur, serta produktif (Diener \& Tay, 2015). Dalam penelitian lain juga sejalan bahwa subjective well-being yang tinggi seperti kepuasaan hidup, tidak adanya emosi negatif, optimisme dan emosi positif yang berpengaruh terhadap tingkat kesehatan dan umur panjang yang lebih baik (Diener \& Chan, 2011). Schiffrin dan Nelson (2010) menyebutkan bahwa subjective well-being juga memiliki hubungan dengan tingkat stress dimana individu yang memiliki tingkat stress yang tinggi memiliki tingkat kebahagiaan yang rendah sedangkan individu yang memiliki tingkat stress rendah memiliki tingkat kebahagiaan yang tinggi. Subjective well-being merupakan kebutuhan dasar, yang mana subjective well-being ini linear dengan pendapatan dan tidak berkurang saat pendapatan meningkat (Stevenson \& Wolfers, 2013).

Banyak individu yang menghabiskan waktu dan tenaga untuk mencapai kepuasan dalam hidupnya. Subjective well-being lebih berfokus pada evaluasi individu terhadap hidupnya. Evaluasi yang dimaksud dalam hal ini meliputi aspek kognitif dan afektif (Diener, 2000). Hal ini diperkuat dengan (Diener, 2009) yang mengatakan bahwa subjective well-being merupakan bagaimana individu mengevaluasi hidupnya.Subjective well-being melibatkan evaluasi pada dua komponen, yaitu kognitif dan afektif. Tingkat subjective well-being yang tinggi ditandai dengan adanya evaluasi kognitif, yaitu berupa tingginya kepuasan hidup (life satisfaction) serta evaluasi afektif berupa tingginya afek positif (positive affect), dan rendahnya afek negatif (negative affect). Subjective well-being merupakan sebuah konsep yang luas mengenai bentuk evaluasi kehidupan seseorang atau pengalaman emosionalnya, yang merupakan gabungan dari tingginya kepuasan hidup, tingginya afek positif, dan rendahnya afek negatif. Seseorang yang memiliki tingkat subjective well-beingyang tinggi memiliki mampu mengatur emosi, dan menghadapi masalah dengan baik. Sebaliknya orang yang memiliki tingkat subjective-well-being yang rendah cenderung merasa hidupnya tidak bahagia, penuh perasaan pikiran dan perasaan negatif sehingga menimbulkan kecemasan, kemarahan, bahkan berisiko mengalami depresi (Diener, Oishi, \& Lucas, 2015).

Penelitian ini bertujuan untuk mengkaji hasil-hasil penelitian mengenai faktor-faktor yang mempengaruhi subjective well-being pada individu. Diharapkan melalui penelitian ini, dapat diketahui lebih mendalam mengenai subjective well-being dan berguna untuk penelitian selanjutnya. 
Jurnal Psikologi Terapan dan Pendidikan

ISSN: $2715-2456$

Vol. 1, No. 1, Mei 2019, pp. 54-62

\section{METODE PENELITIAN}

\section{Strategi Penelusuran}

Penelitian ini termasuk pada penelitian systematic review dengan menggunakan metode kualitatif (meta-sintesis). Lalu, pendekatan yang digunakan dalam penelitian ini adalah meta-etnograf, yaitu peneliti merangkum berbagai hasil penelitian yang relevan secara naratif dengan tujuan mengembangkan teori baru untuk melengkapi teori yang sudah ada (Siswanto, 2010).

Penelusuran dilaksanakan pada tanggal 4 Agustus 2019 yaitu penelusuran hasil penelitian di database elektronik seperti SAGE Journals (http://journals.sagepub.com/), ProQuest (https://search.proquest.com/) dan Science Direct (http://www.sciencedirect.com/). Database elektronik tersebut menyediakan berbagai artikel publikasi pada berbagai disiplin ilmu, seperti kesehatan,sosial, teknik, dan medis. Database elektronik tersebut dipilih karena mengindeks lebihbanyak hasil-hasil penelitian di bidang sosial khususnya psikologi.Kurun waktu periodepublikasi dibatasi mulai tahun 2010 hingga 2019.

\section{Kriteria Seleksi}

Dari hasil penelusuran yang telah dilakukan, peneliti membaca judul dan abstrak penelitian untuk mengetahui apakah artikel tersebut memenuhi kriteria untuk dikaji. Kriteria yang digunakan adalah: 1) artikel penelitian membahas tentang subjective well-being; 2) artikel membahas tentang pengaruh variabel "X" terhadap subjective well-being; 3) artikel berisi laporan hasil penelitian (original article); 4) artikel ditulis dalam Bahasa Inggris. Peneliti memperoleh 30 artikel publikasi tetapi setelah proses seleksi, hanya 28 artikel publikasi yang relevan untuk dikaji. Dua artikel publikasi yang lain tidak relevan karena tidak membahas mengenai pengaruh variabel "X" terhadap subjective well-being.

\section{Analisis}

Pada penelitian ini peneliti melakukan identifikasi, evaluasi, dan interpretasi terhadap semua hasil penelitian yang relevan terkait subjective well-being secara naratif. Peneliti mengumpulkan 28 artikel publikasi yang relevan untuk dikaji dan membuat rangkuman hasil-hasil penelitian yang mencakup nama peneliti, tahun publikasi, jumlah subjek, alat ukur yang digunakan, dan hasil penelitian. Dari hasil tersebut, peneliti menarik kesimpulan mengenai faktor-faktor yang mempengaruhi subjective well-being.

\section{HASIL}

Berdasarkan hasil analisis pada 28 artikel publikasi yang relevan untuk dikaji, diperolehhasil sebagai berikut. 
Jurnal Psikologi Terapan dan Pendidikan

ISSN: $2715-2456$

Vol. 1, No. 1, Mei 2019, pp. 54-62

\section{Dukungan Sosial}

Dukungan sosial menjadi salah satu faktor yang dapat mempengaruhi subjective well-being seseorang individu. Hasil analisis data pada 87 siswa yang terdaftar di departemen pelatihan guru oleh Gulacti (2010) menemukan bahwa subjective well-being memberikan pengaruh yang signifikan terhadap dukungan sosial. Hal ini didukung oleh penelitian yang dilakukan oleh Brajsa-zganec (2017) pada 1000 orang dewasa di Kroasia dimana juga menemukan bahwa subjective well-being signifikan terhadap dukungan sosial. Selanjutnya penelitian yang dilakukan oleh Siedlecki dan Salthouse (2013) yang menunjukan bahwa subjective well-being signifikan terhadap dukungan sosial, penelitian dilakukan pada 1111 orang dengan rentang usia 18-95 tahun. Hasil analisis data lainnya pada 1332 siswa perguruan tinggi yang berasal dari tiga Negara, yaitu Jepang (466 siswa), Cina (449 siswa), dan Korea (417 siswa) oleh Matsuda, Tsuda, Kim dan Deng (2014) menemukan bahwa subjective well-being memberikan pengaruh yang signifikan terhadap dukungan sosial. Selanjutnya penelitian oleh Xi, Wang, dan Jia (2017) pada mahasiswa di Cina, yang menemukan bahwa subjective well-being memberikan pengaruh yang signifikan terhadap dukungan sosial. Penelitian ini memiliki tujuan melihat subjective well-being seseorang dengan melihat latar belakang berbagai macam budaya sebagai bentuk dukungan sosialnya.

\section{Kebersyukuran}

Kebersyukuran juga dapat mempengaruhi subjective well-being. Datu (2013) melakukan penelitian pada 210 siswa di Filipina, hasil menunjukan bahwa kebersyukuran memberikan pengaruh yang signifikan terhadap subjective well-being .Hal ini didukung oleh penelitian Kong, Ding, dan Zhao (2014) pada 427 sarjana di Negara Cina. Hasil menunjukan bahwa kebersyukuran memberikan pengaruh yang signifikan terhadap subjective well-being . Selanjutnya penelitian lain menujukan hal yang serupa, penelitian dilakukanoleh Chan (2013) pada 143 guru Cina-Hongkong. Hasil analisis data lainnya pada penelitian eksperimen yang dilakukan oleh Martinez-marti, Avia, dan Hernands-Loreda (2010) yang menunjukan bahwa kebersyukuran memberikan pengaruh positif yang signifikan terhadap subjective well bein, yang dapat dilihat dari ahsil pre-test dan post-test pada mahasiswa Psikologi. Jackowska, Brown, Ronaldson, dan Steptoe (2015)juga melakukan penelitian antara subjective well-being dengan kebersyukuran. Hasil menunjukan signifikan dimana ada pengaruh antara subjective well dan kebersyukuran. Penelitian dilakukan pada 119 perawat muda dengan menggunakan metode eksperimen.Selanjutnya penelitian lain pada mahasiswa sebuah universitas dengan jumlah 443 mahasiswanya yang terdiri dari 321 perempuan dan 110 laki-laki oleh Sapmaz, Yildirim, Topcuoglo, Nalbant, dan Sizir (2015). Hasilnya menunjukan bahwa terdapat pengaruh antara subjective well-being dengan kebersyukuran. 
Jurnal Psikologi Terapan dan Pendidikan

ISSN: $2715-2456$

Vol. 1, No. 1, Mei 2019, pp. 54-62

\section{Forgiveness}

Forgiveness juga dapat mempengaruhi subjective well-being seseorang. Hal ini dibuktikan oleh beberapa penelitian yang telah dilakukan. Penelitian pertama dilakukan oleh Allemand, Patrick, Ghaemmaghami, dan Martin (2012) yang dilakukan pada 962 orang dewasa dengan rentang usia 19-84 tahun. Hasil menunjukan bahwa forgiveness memberikan pengaruh yang positif terhadap subjective wellbeing. Penelitian kedua dilakukan pada 142 guru Cina-Hongkong oleh Chan (2012) yang juga mempunyai hasil bahwa bahwa forgiveness memberikan terhadap subjective well-being .Selanjutnya penelitian ketiga oleh Datu (2013) yang melakukan penelitian pada 210 siswa di Filipina dan hasilnya juga signifikan antara subjective well-being dengan forgiveness. Roxas, David, dan Aruta (2019) juga melakukan penelitian tentang subjective well-being denganforgiveness, hasil analisis menunjukan bahwa hipotesis diterima sehingga hasilnya signifikan. Penelitian ini di lakukan pada 231 konseling professional di Filipina. Selanjutnya pada penelitian kelima ditemukan bahwa hasil analisis data pada 482 mahasiswa oleh Yalcin dan Malkoc (2014) juga ditemukan bahwa forgiveness memberikan pengaruh yang positif terhadap subjective well-being.

\section{Personality}

Jovanovic (2010) menemukan bahwa personality memberi pengaruh signifikan kepada subjective well-being. Penelitian ini memiliki tujuan untuk menyelidiki peran ciri-ciri kepribadian dalam memprediksi subjective well-being. Penelitian lain dilakukan oleh Malkoc (2011) pada 251 mahasiswa sarjana di Universitas Marmara. Hasil penelitian menunjukan bahwa masing-masing kepribadian ada yang memiliki hubungan positif terhadapsubjective well-being, ada juga yang tidak memiliki hubungan positif terhadap subjective well-being. Selanjutnya penelitian yang dilakukan oleh Stead dan Bibby (2017) yang menunjukan bahwa kepribadian mempengaruhi subjective well-being seseorang. Penelitian dilakukan pada 495 peserta usia 18-30 tahun. Penelitian selanjutnya dilakukan oleh Liu (2014) pada 193 peserta dalam tujuh kelompok seni di Cina bagian Timur. Penelitian ini menunjukan bahwa extraversion berkolerasi positif dengan subjective well-being, sedangkan neurotisme berpengaruh negatif dengan subjective well-being.

\section{Self Esteem}

Pengaruh dari self esteem terhadap subjective well-being ditemukan pada penelitian yang dilakukan oleh Kong, Zhao, dan You (2012) pada 391 mahasiswa dimana hasilnya menunjukan bahwa self esteem memberikan pengaruh yang signifikan terhadap subjective well-being. Hasil yang sama juga ditemukan oleh Li, Lan, dan Ju (2015) pada 542 siswa dengan 217 laki-laki dan 325 perempuan rentang usia 17-24 tahun. Hasil menunjukan bahwa self esteem memberikan pengaruh yang signifikan terhadap 
Jurnal Psikologi Terapan dan Pendidikan

ISSN: $2715-2456$

Vol. 1, No. 1, Mei 2019, pp. 54-62

subjective well-being .Penelitian selanjutnya dilakukan oleh Khalek (2010) pada 499 muslim Kuwait, hasil penelitian menunjukan bahwa self esteem memberikan pengaruh positif terhadap subjective wellbeing . Selanjutnya Joshanloo dan Daemi (2014) menemukan bahwa terdapat hubungan antara self esteem dengansubjective well-being .

\section{Spiritualitas}

Penelitian Liu (2014) menyebutkan bahwa spiritualitas memberikan pengaruh terhadap subjective well-being. Penelitian dilakukan pada 193 peserta dalam tujuh kelompok seni di Cina bagian Timur. Selanjutnya Joshanloo dan Daemi (2014) menemukan bahwa terdapat hubungan antara spiritualitas dengan subjective well-being .Penelitian selanjutnya dilakukan oleh Khalek (2010) pada 499 muslim

Kuwait, hasil penelitian menunjukan bahwa spiritualitasmemberikan pengaruh positif terhadap subjective well-being.

\section{PEMBAHASAN}

Pada penelitian ini, ditemukan 28 artikel yang relevan untuk dikaji terkait faktor-faktor yang mempengaruhi subjective well-being. Dari 28 artikel publikasi, 6 artikel melibatkan siswa sebagai subjek penelitian, 8 artikel melibatkan mahasiswa, 8 artikel melibatkan masyarakat, 2 artikel melibatkan guru, 1 artikel melibatkan konseling professional, 1 artikel melibatkan perawat dan 2 artikel melibatkan muslim Kuwait. Hal tersebutmenunjukkan bahwa subjective well-being ditemukan pada berbagai lingkup masyarakat, termasuk mahasiswa dan siswa.Karena semua orang melakukan berbagai cara agar dapat merasakan kesejahteraan dalam hidupnya, dengan tujuannya agar bahagia.

Mayoritas dari 28 artikel publikasi tersebut menggunakan alat ukur subjective well-being milik Diener (1984). Hal tersebut dapat dikarenakan Diener (1984) merupakan tokoh pertama yang menyusun alat ukur yang valid dan reliabel untuk digunakan dalam mengukur subjective well-being. Berdasarkan kajian pada 28 artikel publikasi diketahui bahwa subjective well-being dipengaruhi oleh berbagai faktor, antara lain dukungan sosial, kebersyukuran, forgiveness, self esteem, dan spiritualitas.

Pada penelitian ini, peneliti memasukkan variabel-variabel tersebut dalam 2 kategoriyaitu faktor internal dan eksternal. Faktor internal adalah faktor-faktor yang muncul dari dalam diri individu sedangkan faktor eksternal adalah faktor yang muncul dari luar diriindividu. Faktor internal yang mempengaruhi subjective well-being, yaitu: Kebersyukuran (Datu, 2013; Kong, Ding, \& Zhao, 2014; Chan, 2013; Martinez-marti, Avia, \& Hernands-loreda, 2010; Jackowska, Brown, Ronaldson \& Steptoe, 2015; Sapmaz, Yildirm, Topcuoglo, Nalbant, \& Sizir, 2015), forgiveness (Allemand, Patrick, Ghaemmaghami, \& Martin, 2012; Chan, 2013; Datu, 2013; Roxas, David, \& Aruta, 2019; Yalcin \& Malkoc, 2014), Personality (Jovanofic, 2010; Malkoc, 2011; Stead \& Bibby, 2017; Liu, 2014), Self 
Jurnal Psikologi Terapan dan Pendidikan

ISSN: $2715-2456$

Vol. 1, No. 1, Mei 2019, pp. 54-62

esteem (Kong, Shao, \& You, 2012; Li, Lan, \& Ju; 2015; Khalek, 2010; Joshanloo \& Daemi, 2014), Spiritualitas (Liu, 2014; Joshanloo \& Daemi, 2014; Khalek, 2010). Adapun, faktor eksternal yang mempengaruhi subjective well-being, yaitu dukungan sosial (Gulacti, 2010; Brajsa-zganec, 2017; Siedlecki \& Salthouse, 2013; Matsuda, Tsuda, Kim, \& Deng, 2014; Xi, Wang, Jia, 2017).

Keterbatasan dalam penelitian ini adalah kesulitan untuk mengakses artikel publikasisecara fulltext (lengkap).Mayoritas dari artikel penelitian yang dipublikasikan secara online, hanya menyajikan abstrak dari penelitiannya saja.Selain itu, masih jarangditemukan penelitian tentang subjective well-being di Indonesia sehingga peneliti memilihuntuk menggunakan artikel publikasi dalam internasional (berbahasa Inggris).

\section{KESIMPULAN}

Hasil studi menunjukkan bahwa subjective well-being tidak hanya dipengaruhi oleh faktor dari dalam diri individu saja (internal), tetapi juga dapat dipengaruhi oleh faktor dari luar (eksternal). Faktor internal terdiri dari kebersyukuran, forgiveness, personality, self esteem, dan spiritualitas. Sedangkan faktor eksternal terdiri dari dukungan sosial, Peneliti belum menemukan penelitian yang membahas mengenai intervensi yang dapatmeningkatkan subjective well-being baik dalam setting individu, kelompok atau komunitas.Disarankan pada peneliti selanjutnya untuk mengembangkan penelitian terkait intervensipada subjective well-being. Selain itu, peneliti selanjutnya dapat menggunakan subjek lain yang lebih beragam dan mengembangkan alat ukur terbaru untuk mengukur subjective well-being.

\section{DAFTAR PUSTAKA}

Abdel-Khalek, A. M. (2009). Religiosity, subjective well-being, and depression in Saudi children and adolescents. Mental Health, Religion \& Culture, 12(8), 803-815. Doi:10.1080/13674670903006755.

Abdel-Khalek, A. M. (2011). Religiosity, subjective well-being, self-esteem, and anxiety among Kuwaiti Muslim adolescents. Mental Health, Religion \& Culture, 14(2), 129-140. Doi:10.1080/13674670903456463.

Allemand, M., Hill, P. L., Ghaemmaghami, P., \& Martin, M. (2012). Forgivingness and subjective wellbeing in adulthood: The moderating role of future time perspective. Journal of Research in Personality, 46(1), 32-39. Doi:10.1016/j.jrp.2011.11.004.

Bukhari, R. \& Khanam, S. J. (2015). Happiness and life satisfaction among depressed and non depressed university student. Journal of Clinical Psychology. 14 (2), 49-59.

Chan, D. W. (2013). Subjective well-being of Hong Kong Chinese teachers: The contribution of gratitude, forgiveness, and the orientations to happiness. Teaching and Teacher Education, 32, 22-30. Doi:10.1016/j.tate.2012.12.005. 
Chan, D. W. (2013). Subjective well-being of Hong Kong Chinese teachers: The contribution of gratitude, forgiveness, and the orientations to happiness. Teaching and Teacher Education, 32, 22-30. Doi:10.1016/j.tate.2012.12.005.

Datu, J.A (2013). Forgiveness, gratitude and subjective well-being among Filipino adolescents. International Journal for the Advancement of Counselling, 36(3), 262-273. Doi:10.1007/s10447-013-9205-9.

Diener, E., \& Chan, M.Y. (2011). Happy people live longer: subjective well-being contributes to health and longevity. Applied Psychology: Health and Well-Being, 3, 1-43.

Diener, E., \& Tay, L. (2015). Subjective well-being and human welfare around the world as reflecte in the Gallup World Poll. International Journal of Psychology, 50(2), 135-149.

Diener, E., Oishi, S., \& Lucas, R.E. (2015). National accounts of subjective well-being. American Psychologist, 70, 234-242.

Garssen, B., Visser, A., \& De Jager Meezenbroek, E. (2016). Examining whether spirituality predicts subjective well-being: How to avoid tautology. Psychology of Religion and Spirituality, 8(2), 141-148. Doi:10.1037/rel0000025.

Gülaçtı, F. (2010). The effect of perceived social support on subjective well-being. Procedia -Social and Behavioral Sciences, 2(2), 3844-3849. Doi:10.1016/j.sbspro.2010.03.602.

Jackowska, M., Brown, J., Ronaldson, A., \& Steptoe, A. (2016). The impact of a brief gratitude intervention on subjective well-being, biology and sleep. Journal of Health Psychology, 21(10), 2207-2217. Doi:10.1177/1359105315572455.

Joshanloo, M., \& Daemi, F. (2014). Self-esteem mediates the relationship between spirituality and subjective well-being in Iran. International Journal of Psychology, 50(2), 115-120. Doi:10.1002/ijop.12061.

Jovanovic, V. (2011). Personality and subjective well-being: One neglected model of personality and two forgotten aspects of subjective well-being. Personality and Individual Differences, 50(5), 631635. Doi:10.1016/j.paid.2010.12.008.

Kong, F., Ding, K., \& Zhao, J. (2014). The relationships among gratitude, self-esteem, social support and life satisfaction among undergraduate students. Journal of Happiness Studies, 16(2), 477-489. Doi:10.1007/s10902-014-9519-2.

Kong, F., Zhao, J., \& You, X. (2012). Self-esteem as mediator and moderator of the relationship between social support and subjective well-being among chinese university students. Social Indicators Research, 112(1), 151-161. Doi:10.1007/s11205-012-0044-6.

Li, Y., Lan, J., \& Ju, C. (2015). Self-esteem, gender, and the relationship between extraversion and subjective well-being. Social Behavior and Personality: An International Journal, 43(8), 12431254. Doi:10.2224/sbp.2015.43.8.1243.

Liu, H. (2014). Personality, leisure satisfaction, and subjective well-being of serious leisure participants. social behavior and personality. An International Journal, 42(7), 1117-1125. Doi:10.2224/sbp.2014.42.7.1117.

Malkoç, A. (2011). Big five personality traits and coping styles predict subjective well-being: A study with a Turkish Sample. Procedia - Social and Behavioral Sciences, 12, 577-581. Doi:10.1016/j.sbspro.2011.02.070. 
Martínez-Martí, M. L., Avia, M. D., \& Hernández-Lloreda, M. J. (2010). The effects of counting blessings on subjective well-being: A gratitude intervention in a spanish sample. The Spanish Journal of Psychology, 13(02), 886-896. Doi:10.1017/s1138741600002535.

Roxas, M. M., David, A. P., \& Aruta, J. J. B. R. (2019). Compassion, forgiveness and subjective wellbeing among filipino counseling professionals. International Journal for the Advancement of Counselling. Doi:10.1007/s10447-019-09374-w .

Sapmaz, F., Yıldırım, M., Topçuoğlu, P., Nalbant, D., \& Sızır, U. (2016). gratitude, forgiveness and humility as predictors of subjective well-being among university students. International Online Journal of Educational Sciences, 8 (1), 38-47.

Schiffrin, H. H., \& Nelson, S. K. (2010). Stressed and happy? investigating the relationship between happiness and perceived stress. Journal Happiness Study, 11(1), 33-39.

Siedlecki, K. L., Salthouse, T. A., Oishi, S., \& Jeswani, S. (2013). The relationship between social support and subjective well-being across age. Social Indicators Research, 117(2), 561-576. Doi:10.1007/s11205-013-0361-4.

Stead, H., \& Bibby, P. A. (2017). Personality, fear of missing out and problematic internet use and their relationship to subjective well-being. Computers in Human Behavior, 76, 534-540. Doi:10.1016/j.chb.2017.08.016.

Stevenson, B., \& Wolfers, J. (2013). Subjective Well-Being and Income: Is There Any Evidence of Satiation?. National Bureau of Economic Research: Cambridge.

Wills, E. (2009). Spirituality and subjective well-being: Evidences for a new domain in the personal wellbeing index. Journal of Happiness Studies, 10(1), 49-69. Doi:10.1007/s10902-007-9061-6.

Yalçın, İ., \& Malkoç, A. (2014). The relationship between meaning in life and subjective well-being: forgiveness and hope as mediators. Journal of Happiness Studies, 16(4), 915-929. Doi:10.1007/s10902-014-9540-5. 